\title{
Pengendalian Kestabilan Ketinggian pada Penerbangan Quadrotor dengan Metode PID Fuzzy
}

\author{
Panca Agung Kusuma* ${ }^{1}$, Andi Dharmawan ${ }^{2}$ \\ ${ }^{1}$ Program Studi Elektronika dan Instrumentasi, FMIPA UGM, Yogyakarta \\ ${ }^{2}$ Departemen Ilmu Komputer dan Elektronika, FMIPA UGM, Yogyakarta \\ e-mail: *11panca.ak@gmail.com, ${ }^{2}$ dharmawan.andi@gmail.com
}

\begin{abstract}
Abstrak
Quadrotor merupakan salah satu jenis wahana tanpa awak yang memiliki kemampuan lepas landas secara vertikal serta mampu mempertahankan posisinya pada saat terbang. Dalam menerbangkan quadrotor terkadang dibutuhkan ketinggian yang stabil untuk menjalankan misi tertentu. Dengan ketinggian yang stabil akan memudahkan pilot dalam mengendalikan pesawat untuk bergerak ke suatu arah.

Pada penelitian ini dirancang dan dibuat sistem yang mampu menstabilkan ketinggian quadrotor dengan menggunakan metode PID Fuzzy. Sistem kendali ketinggian dibutuhkan untuk membantu pilot mengendalikan kestabilan ketinggian quadrotor tanpa perlu mengatur throttle. Kendali dengan metode PID merupakan salah satu sistem kendali yang umum diterapkan pada quadrotor. Kendali ini mempunyai konstanta yang dapat ditala menggunakan logika fuzzy dengan pendekatan linguistik untuk memperbaiki tanggap waktu sistem pada saat mengatasi error.

Hasil penelitian menunjukkan metode kendali PID Fuzzy menghasilkan tanggap waktu yang lebih baik dibandingkan dengan metode PID saja. Implementasi kendali PID menghasilkan kendali kestabilan ketinggian dengan nilai rerata steady state error sebesar $\pm 1,86 \mathrm{~cm}$, sedangkan PID Fuzzy menghasilkan nilai rerata steady state error sebesar $\pm 1,22 \mathrm{~cm}$.
\end{abstract}

Kata kunci-UAV, quadrotor, PID, fuzzy, ketinggian

\section{Abstract}

Quadrotor is a kind of unmanned aerial vehicle that have the ability to take of vertically and maintaining its position while flying mid-air. Flying a quadrotor sometimes needs a stable altitude to perform a specific mission. A stable altitude will make easier for pilot to control the movement of the quadrotor to certain direction.

This study designed and implemented a system that can stabilises the altitude of a quadrotor by using Fuzzy-PID method. Altitude control system needed to help pilot controls the altitude stability without adjusting the throttle. Control with PID method is a common control system to be implemented on a quadrotor. This control system has a constant that can be tuned with fuzzy logic with linguistic approach to improve the response time when compensating an error.

The result of this study shows that Fuzzy PID control method generate a better response time compared with the PID-only method. The implementation of PID control generate an altitude stabilisation with a mean value steady state error of $\pm 1,86 \mathrm{~cm}$, whereas the PID Fuzzy generate a mean value of steady state error of $\pm 1,22 \mathrm{~cm}$.

Keywords-UAV, quadrotor, PID, fuzzy, altitude 


\section{PENDAHULUAN}

$\mathrm{K}$ emajuan teknologi di berbagai bidang membuat manusia semakin mudah menjalankan suatu pekerjaan. Salah satu produk teknologi yang semakin banyak dipakai dan dikembangkan adalah unmanned air vehicle (UAV) atau pesawat terbang tanpa awak. UAV merupakan wahana terbang tanpa awak yang biasa dikendalikan dari jarak jauh maupun secara autonomous. Pengguna UAV tersebar dari kalangan militer, ilmuan, hingga keperluan sipil lain. UAV secara umum dibagi menjadi 2 macam yaitu fixed-wing dan rotary-wing.

Quadrotor merupakan salah satu jenis UAV tipe rotary-wing yang mempunyai penggerak berupa 4 buah rotor yang disusun secara simetris. Pesawat ini dapat lepas landas dan mendarat secara vertikal atau biasa disebut Vertical Take-off and Landing (VTOL). Rancangan quadrotor cukup sederhana karena tidak memerlukan penggerak lain untuk dapat melakukan berbagai gerakan yaitu roll, pitch, dan yaw. Kesederhanaan rancangan mekanik ini memberi dampak yang cukup besar dalam hal kerumitan kendalinya [1]. Perbedaan gaya dorong sekecil apapun pada salah satu rotor dapat mempengaruhi gerakannya. Selain itu karakteristik motor yang berbeda-beda menambah tingkat kesulitan dalam memodelkan kendali quadrotor.

Kesederhanaan rancangan mekanik quadrotor memiliki keunggulan dalam pembuatan dan pengaplikasiannya. Sehingga quadrotor dapat dirancang sesuai keinginan untuk menjalankan suatu misi. Pada saat menjalankan misi tertentu, terkadang quadrotor memerlukan suatu mode seperti menahan ketinggian. Tujuan menahan ketinggian antara lain untuk menghindari halangan. Pada proses ini quadrotor masih tetap bisa bergerak bebas bebas secara horizontal. Dalam mempertahankan ketinggian quadrotor memerlukan kendali yang stabil agar dapat mempertahankan ketinggian apabila menerima gangguan.

Untuk memudahkan pengendalian quadrotor diperlukan teknik kendali yang baik. Ada berbagai macam teknik kendali yang dapat diterapkan untuk mengendalikan kestabilan ketinggian, salah satunya adalah PID (Proportional Integral Derivative). Kendali PID merupakan salah satu teknik kendali yang sudah banyak digunakan dalam berbagai bidang. Teknik ini banyak digunakan karena kita bisa mengatasi berbagai masalah kendali hanya dengan mengubah nilai gain $K p, K i$, dan $K d$ PID. Penalaan nilai koefisien yang tepat akan menghasilkan kendali yang stabil. Akan tetapi, kendali PID ditujukan pada sistem yang linier untuk dapat bekerja dengan optimal [2]. Hal ini tentu merupakan salah satu kekurangan PID jika diterapkan pada quadrotor yang pada kenyataannya memiliki dinamika nonlinier [3]. Ada beberapa metode nonlinier yang dapat digunakan untuk melakukan penalaan konstanta $K p, K i$, dan $K d$ agar dapat memenuhi kebutuhan kendali quadrotor. Salah satu metode penalaan nonlinier yaitu dengan memanfaatkan logika Fuzzy. Logika fuzzy bekerja dengan meniru logika manusia dalam hal penalaran dan belajar. Sebagai contoh saat kita belajar mengendarai sepeda kita harus mencoba sendiri dengan mempraktekkan secara langsung dan belajar dari kesalahan. Kita belum tentu bisa langsung mengendarai sepeda hanya dengan mengetahui teorinya saja. Dengan memanfaatkan logika Fuzzy, sifat nonlinier quadrotor dapat diatasi karena tidak terpaku pada model matematika yang pada kenyataannya quadrotor mempunyai berbagai faktor yang dapat mempengaruhi kestabilan terbang [4]. Oleh karena itu, dua metode ini dapat digunakan untuk mengatasi sistem kendali quadrotor yang nonlinier.

\section{METODE PENELITIAN}

\subsection{Analisis Sistem}

Quadrotor yang digunakan juga menggunakan logika fuzzy untuk mengoptimalkan konstanta PID. Logika fuzzy akan bertugas sebagai penala otomatis konstanta PID yang

IJEIS Vol. 7, No. 1, April 2017: $61-70$ 
digunakan sistem berdasarkan umpan balik berupa nilai error dan delta error. Sistem ini memiliki konfigurasi (+) sehingga pergerakan roll dan pitch-nya dipengaruhi oleh dua buah rotor yang disusun secara simetris.

Quadrotor yang akan dibuat memiliki 4 buah rotor dengan konfigurasi (+) yang disusun simetris. Perbedaannya terdapat pada kemampuan sistem untuk menahan ketinggian. Untuk memberikan umpan balik nilai ketinggian pesawat dibutuhkan sebuah sensor ketinggian. Untuk memudahkan pengujian di ruangan yang terbatas maka akan digunakan sensor ultrasonik yang dipasang tegak lurus dengan sumbu horisontal pesawat. Sensor yang digunakan adalah sensor ultrasonik tipe HC-SRF04. Pancaran sinyal sensor ini adalah sebesar 15 derajat. Sehingga dapat mentoleransi \pm 7,5 derajat sudut kemiringan quadrotor. Sensor ini mempunyai kemampuan mengukur jarak dari 2 hingga $400 \mathrm{~cm}$. namun akurasi sensor paling optimal dari sensor ini ada pada rentang 15 hingga $200 \mathrm{~cm}$.

Metode pengendalian yang akan digunakan adalah kendali PID yang terbukti keandalannya untuk penerapan pada berbagai bidang. Penggunaan metode ini pada quadrotor sudah banyak dijumpai karena kemampuannya mengatasi sifat dinamis sistem quadrotor seperti yang dilakukan oleh [1]. Kinerja kendali PID ini akan optimal dengan penalaan yang baik. Penalaan dilakukan untuk memperoleh konstanta PID yang akan mempengaruhi karakteristik sistem seperti rise time, settling time, overshoot, dan steady state error. Untuk memperoleh nilai konstanta PID suatu sistem dapat dilakukan dengan menggunakan metode Ziegler-Nichols (ZN). Metode ini digunakan karena mudah diterapkan pada sistem yang rumit seperti quadrotor tanpa memerlukan model matematikanya karena bisa langsung diuji coba pada sistem yang akan ditala. Nilai gain yang didapat mungkin akan menghasilkan tanggapan yang kurang baik sehingga memerlukan fine tuning sampai mendapatkan tanggapan sistem yang diinginkan[5].

Kekurangan metode ini untuk digunakan pada quadrotor adalah karena PID bekerja optimal pada sistem linier yang mengacu pada persamaan matematis, sedangkan quadrotor merupakan sistem non linier. Ketidaklinieran sistem quadrotor dipengaruhi hal-hal seperti karakteristik motor, baterai, kelembaman rangka, dan sebagainya. Untuk mengatasi hal tersebut pada penelitian ini dibuat sistem kendali PID fuzzy yang dapat membantu mengatasi ketidaklinieran sistem dengan pendekatan pola pikir manusia dalam mengatasi berbagai persoalan dalam kehidupan sehari-hari[6]. Logika fuzzy adalah metode komputasi dengan variabel kata-kata yang dikemukakan oleh Dr. Lotfi A. Zadeh pada tahun 1965. Logika ini menggunakan pendekatan alamiah layaknya manusia dalam menentukan suatu keputusan [7]. Logika fuzzy dapat digunakan untuk mengoptimalkan respon dari sistem kendali PID dengan merujuk pada karakteristik konstanta $K p, K i$, dan $K d[8]$.

Tabel 1 Karakteristik efek $K p, K i$, dan $K d$ pada kendali PID [9]

\begin{tabular}{|c|c|c|c|c|c|}
\hline Closed Loop Response & Rise Time & Overshoot & Settling Time & Steady-State Error & Stability \\
\hline Increasing $\mathrm{K}_{\mathrm{p}}$ & Decrease & Increase & $\begin{array}{c}\text { Small } \\
\text { Increase }\end{array}$ & Decrease & Degrade \\
\hline Increasing $\mathrm{K}_{\mathrm{i}}$ & $\begin{array}{c}\text { Small } \\
\text { Decrease }\end{array}$ & Increase & Increase & Large Decrease & Degrade \\
\hline Increasing $\mathrm{K}_{\mathrm{d}}$ & $\begin{array}{c}\text { Small } \\
\text { Decrease }\end{array}$ & Decrease & Decrease & Minor Change & Improve \\
\hline
\end{tabular}

Dengan melihat Tabel 1 di atas maka dapat diformulasikan aturan fuzzy untuk mengoptimalkan kinerja sistem dengan dasar-dasar sebagai berikut:

1. Jika steady-state besar maka naikan konstanta proporsional

2. Jika respon berosilasi maka naikan konstanta derivatif

3. Jika respon lambat maka naikan konstanta proporsional

4. Jika steady-state error terlalu besar maka sesuaikan konstanta integral

5. Jika overshoot terlalu besar maka turunkan konstanta proporsional

Aturan fuzzy yang dibuat diproses dengan membaca sudut dan ketinggian quadrotor. Berdasarkan setpoint sudut dan ketinggian yang telah ditentukan maka akan didapat nilai error dan delta error yang merupakan indikator keadaan quadrotor. Sistem fuzzy kemudian akan menala secara mandiri agar respon sistem dapat lebih optimal. 
Berdasarkan uraian di atas maka dapat dirumuskan pokok-pokok sistem yang digunakan dalam penelitian ini yaitu sebagai berikut:

1. Sistem kendali yang akan dibuat dapat membantu quadrotor mempertahankan kestabilan ketinggiannya dengan baik berdasarkan jarak dengan permukaan tanah dengan nilai steady-state error maksimum sebesar $5 \mathrm{~cm}$. Kendali tersebut juga harus mempertahankan steady state error sudut roll dan pitchnya sebesar 5\% agar pembacaan sensor ultrasonik masih dapat bekerja dengan baik.

2. Risetime yang dihasilkan untuk sudut pitch dan roll lebih cepat atau sama dengan 1 detik dan untuk sudut yaw dan ketinggian lebih cepat dari 4 detik.

3. Settling time untuk sudut pitch dan roll $\leq 3$ detik, dan sudut yaw serta altitude $\leq 6$ detik.

4. Maximum overshoot pitch dan roll $\leq 10 \%$, dan yaw serta altitude $\leq 20 \%$.

5. Metode kendali yang akan digunakan diptimalkan dengan logika fuzzy yang dapat menala secara mandiri nilai kontstanta $K p, K i$, dan $K d$ pada PID sehingga respon sistem lebih baik.

\subsection{Rancangan Sistem}

Sistem yang dirancang pada penelitian ini adalah sistem kendali sikap terbang quadrotor serta kendali kestabilan ketinggian quadrotor. Rancangan sistem secara keseluruhan meliputi rancangan perangkat keras dan rancangan perangkat lunak, serta rancangan pengujian terhadap sistem kestabilan ketinggian.

\subsubsection{Rancangan arsitektur sistem}

Dalam penelitian ini, mikrokontroler Arduino Due bertugas sebagai unit pemroses masukan dan keluaran sistem. Arduino Due digunakan karena memiliki kapasitas penyimpanan yang cukup besar serta mampu bekerja dengan clock yang tinggi agar metode fuzzy yang digunakan dapat berjalan dengan baik. Terdapat 3 buah sensor masukan yaitu IMU 6 DOF yang terdiri dari Accelerometer dan Gyroscope yang berfungsi untuk memberikan masukan kondisi pitch dan roll, Megnetometer atau kompas HMC5883L sebagai penunjuk arah atau heading, serta sensor ultrasonik HC-SR04 sebagai penunjuk ketinggian quadrotor terhadap permukaan tanah. Untuk keperluan kendali dan pemantuan data digunakan Remote Control (RC) dan Ground Segment berupa sebuah komputer yang terhubung menggunakan modul telemetri. Daya yang diperoleh sistem ini berasal dari baterai LiPo 3 sel. Gambar 1 adalah rancangan arsitektur sistem secara keseluruhan. 


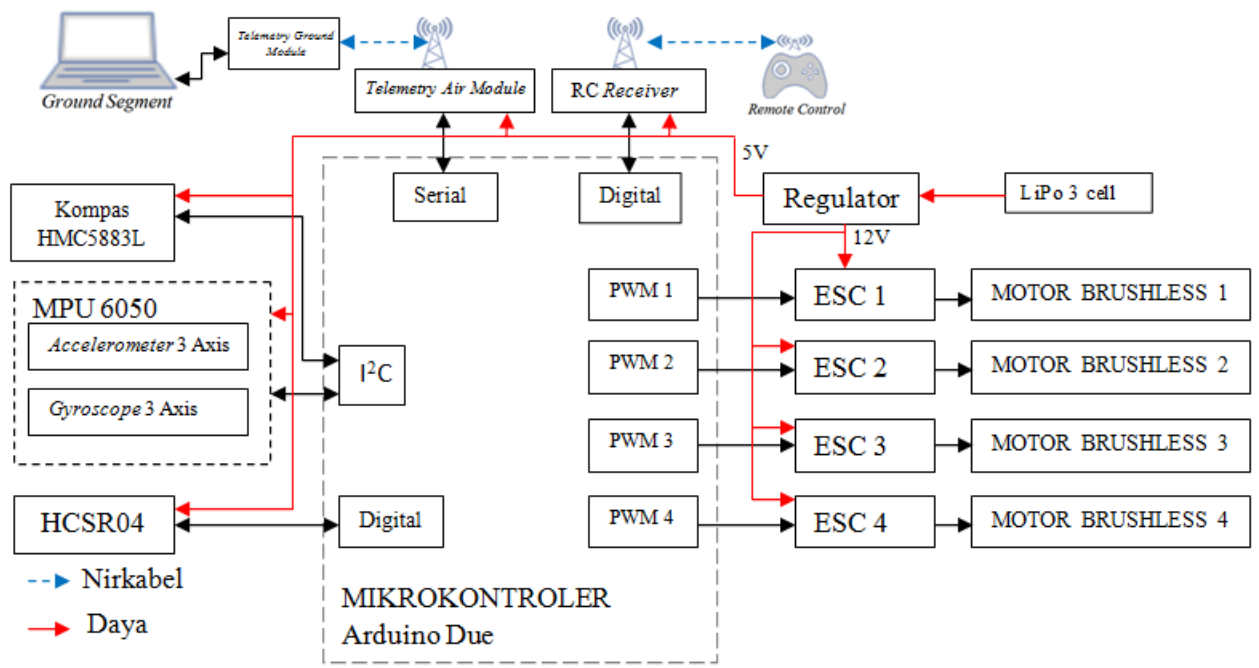

Gambar 1 Rancangan Arsitektur Sistem

\subsubsection{Rancangan sistem kendali}

Pada penelitian ini, terdapat masukan tambahan untuk sistem quadrotor yang berupa sensor ketinggian. Dengan sensor ini, kendali ketinggian akan dilakukan dengan cara menghitung selisih nilai ketinggian quadrotor dan setpoint ketinggian yang diinginkan. Kendali ini untuk memudahkan pengendalian kestabilan ketinggian quadrotor sehingga pilot tidak perlu mengatur throttle.

Logika fuzzy pada rancangan ini akan menghitung nilai konstanta proporsional $(K p)$, integral $(K i)$, dan derivatif $(K d)$ terbaik yang diharapkan dapat memperbaiki respon sistem. PID fuzzy merupakan kombinasi kendali PID dengan logika fuzzy. Logika fuzzy digunakan untuk menala besaran konstanta PID agar diperoleh respon sistem yang lebih baik. Diagram kerja keseluruhan sistem PID Fuzzy dapat dilihat pada Gambar 2.

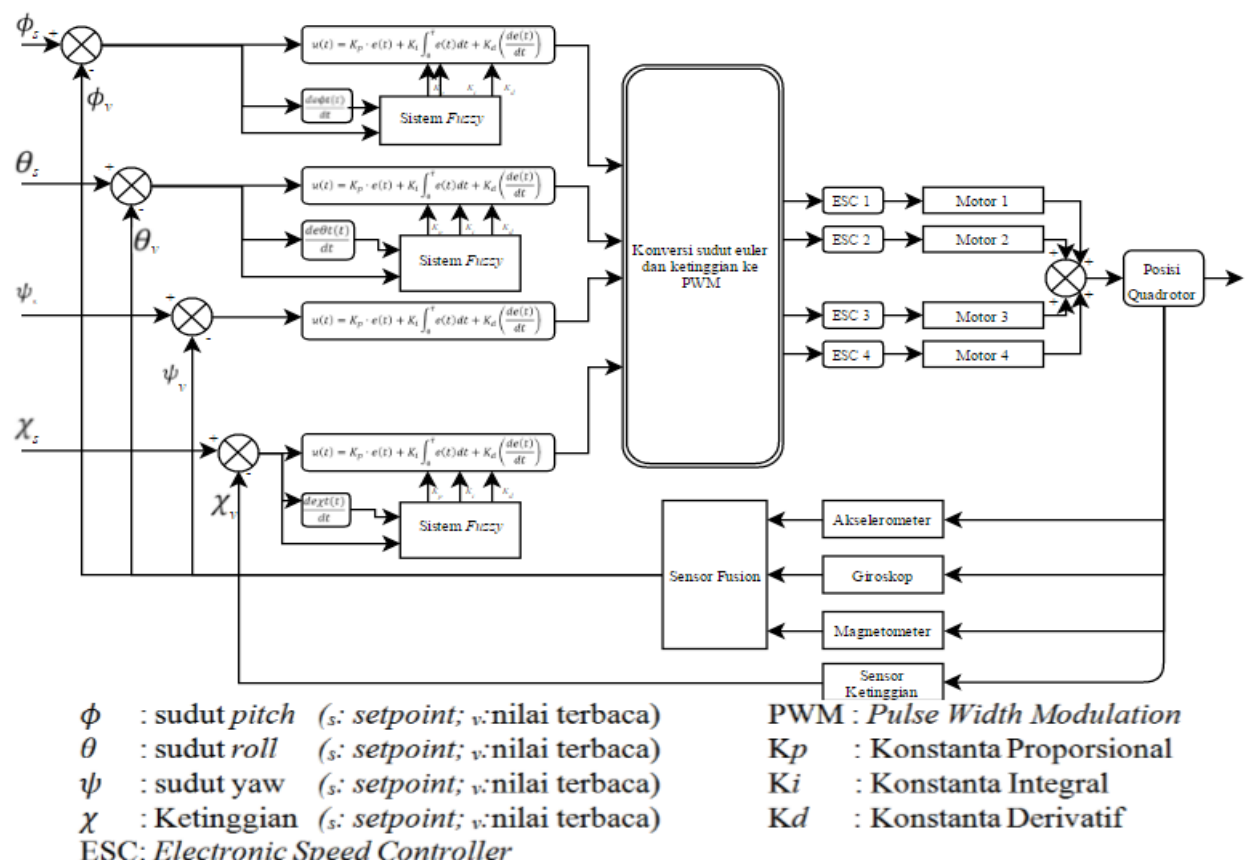

Gambar 2 Diagram kerja PID Fuzzy 
Masukan crisp merupakan masukan hasil penghitungan sensor fusion yang berupa error dan delta error. Error merupakan nilai selisih dari nilai bacaan sensor dan nilai setpoint. Delta error merupakan perubahan nilai error atau selisih nilai error sekarang dan nilai error sebelumnya. Masukan crisp ini kemudian akan masuk ke tahap fuzzifikasi dimana nilai-nilai tersebut akan dimasukkan ke dalam himpunan fuzzy yang berupa lima buah variabel linguistik.

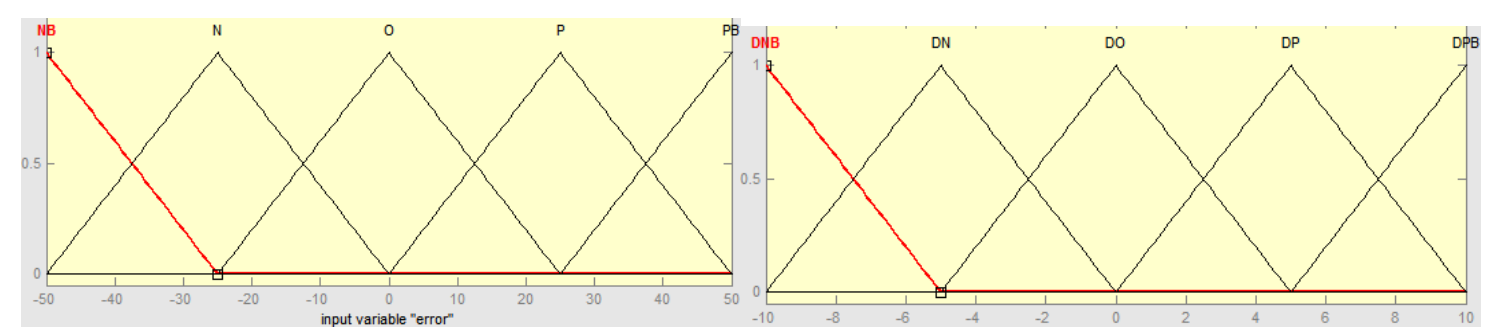

(a)

(b)

Gambar 3 Himpunan fuzzy input pitch dan roll (a) error dan (b) delta error

Variabel-variabel linguistik yang digunakan pada pitch dan roll yaitu NB(Negatif Besar), N (Negatif), O (Nol), P (Positif), dan PB (Positif Besar) untuk masukan error yang kemudian disebut himpunan fuzzy error. Sedangkan untuk masukan delta error menggunakan DNB (Delta Negatif Besar), DN (Delta Negatif), DO (Delta Nol), DP (Delta Positif), dan DPB (Delta Positif Besar) yang kemudian disebut himpunan fuzzy delta error. Pada setiap variabel nantinya akan mempunyai rentang-rentang nilai tersendiri. Penentuan rentang didapat dari penelitian sebelumnya yang dilakukan oleh Pogram [10]. Gambar 3 merupakan rancangan himpunan fuzzy error dan delta error yang dibuat pada software MATLAB menggunakan toolbox fuzzy yang tersedia.

Nilai input ini dianalisa oleh FIS (Fuzzy inference system) dengan menggunakan aturan fuzzy (rule-base) yang telah disusun. Aturan fuzzy (rule base) memiliki bentuk dasar "if " $\mathrm{X}=\mathrm{A}$, "Then" $\mathrm{Y}=\mathrm{B}$, sehingga aturan fuzzy sering disebut juga aturan "If-then". Pada sistem quadrotor ini rule base yang digunakan berdasarkan rancangan himpunan fuzzy untuk error, delta error, $K p, K i$ dan $K d$. Tabel 2 menunjukkan aturan fuzzy yang digunakan untuk menentukan nilai $K p$ dan $K i$. Sedangkan Tabel 3 menunjukkan aturan fuzzy yang digunakan untuk menentukan nilai $K d$. Dengan begitu terdapat 25 aturan fuzzy (rule base) yang digunakan.

Aturan dibuat berdasarkan pada pengaruh perubahan konstanta kendali proporsional, integral, dan derivatif terhadap nilai error dan deltaerror. Tabel hubungan nilai $K p, K i$, dan $K d$ dan dampaknya terhadap respon sistem dapat dilihat pada Tabel 1 . Aturan untuk $K p$ dan $K i$ dibuat sama karena memang dampak kedua kendali terhadap nilai yang dihasilkan sama.

Tabel 1 Fuzzy rule untuk Kp dan Ki

\begin{tabular}{|c|c|c|c|c|c|c|}
\hline & \multicolumn{7}{|c|}{ Error } \\
\hline \multirow{2}{*}{$\lesssim$} & & $\mathrm{NB}$ & $\mathrm{N}$ & $\mathrm{O}$ & $\mathrm{P}$ & $\mathrm{PB}$ \\
\cline { 2 - 7 } & $\mathrm{DNB}$ & $\mathrm{H}$ & $\mathrm{B}$ & $\mathrm{M}$ & $\mathrm{B}$ & $\mathrm{H}$ \\
\cline { 2 - 7 } & $\mathrm{DN}$ & $\mathrm{B}$ & $\mathrm{M}$ & $\mathrm{S}$ & $\mathrm{M}$ & $\mathrm{B}$ \\
\cline { 2 - 7 } & $\mathrm{DO}$ & $\mathrm{M}$ & $\mathrm{S}$ & $\mathrm{T}$ & $\mathrm{S}$ & $\mathrm{M}$ \\
\cline { 2 - 7 } & $\mathrm{DP}$ & $\mathrm{B}$ & $\mathrm{M}$ & $\mathrm{S}$ & $\mathrm{M}$ & $\mathrm{B}$ \\
\cline { 2 - 7 } & $\mathrm{DPB}$ & $\mathrm{H}$ & $\mathrm{B}$ & $\mathrm{M}$ & $\mathrm{B}$ & $\mathrm{H}$ \\
\hline
\end{tabular}

IJEIS Vol. 7, No. 1, April $2017: 61-70$ 
Tabel 2 Fuzzy rule untuk Kd

\begin{tabular}{|c|c|c|c|c|c|c|}
\hline & \multicolumn{6}{|c|}{ Error } \\
\hline \multirow{6}{*}{$\frac{1}{0}$} & & NS & $\mathrm{N}$ & $\mathrm{O}$ & $\mathrm{P}$ & SP \\
\hline & DNS & $\mathrm{T}$ & $\mathrm{S}$ & M & $\mathrm{S}$ & $\mathrm{T}$ \\
\hline & $\mathrm{DN}$ & $\mathrm{S}$ & $\mathrm{M}$ & B & $\mathrm{M}$ & $\mathrm{S}$ \\
\hline & $\mathrm{DO}$ & $\mathrm{M}$ & B & $\mathrm{H}$ & B & M \\
\hline & DP & $S$ & $\mathrm{M}$ & B & $\mathrm{M}$ & $S$ \\
\hline & DPS & $\mathrm{T}$ & $\mathrm{S}$ & $\mathrm{M}$ & $\mathrm{S}$ & $\mathrm{T}$ \\
\hline
\end{tabular}

Keterangan:

NB: Negatif Besar

$\mathrm{T} \quad$ : Sangat Kecil

$\mathrm{N}$ : Negatif

$S$ : Kecil

$\mathrm{O}$ : Tengah

$M$ : Sedang

$\mathrm{P}$ : Positif

B : Besar

\section{PB : Positif Besar $\quad H$ : Sangat Besar}

Nilai negatif dan positif pada error dan deltaerror menghasilkan nilai $K p$ dan $K i$ yang sama untuk digunakan karena hal tersebut bergantung pada orientasi quadrotor. Jika nilai error besar (NB dan $\mathrm{PB}$ ) maka nilai $K p$ dan $K i$ yang digunakan yang paling besar (H). Nilai deltaerror yang terbaca menunjukkan kecepatan respon sistem. Apabila semakin besar nilai deltaerror berarti telah terjadi perubahan error dalam waktu singkat. Nilai $K p$ dan $K i$ akan diperkecil ketika nilai error dan deltaerror semakin mengecil sehingga respon sistem melemah pada saat mendekati titik steady state. Nilai steady state ditunjukkan ketika error dan deltaerror bernilai $\mathrm{O}$ (Tengah), pada keadaan ini diharapkan tidak terjadi perubahan pada sistem sehingga nilai $K p$ dan $K i$ menggunakan yang paling kecil (T).

Pada Tabel $2 K p$ dan $K i$ memiliki aturan yang sama namun berbeda dengan aturan yang digunakan untuk $K d$ pada Tabel 3. Hal tersebut dikarenakan karakteristik $K p$ dan $K i$ memiliki kesamaan dan berbeda dengan karakteristik $K d$. $K p$ dan $K i$ akan memberikan nilai osilasi yang semakin besar bila konstanta yang digunakan semakin besar pula dan osilasi semakin kecil bila konstanta semakin kecil. Sebaliknya $K d$ akan meredam osilasi sehingga semakin besar konstanta semakin kecil osilasi karena teredam dan semakin kecil konstanta, maka semakin besar osilasi. Selain itu, rumus yang digunakan $K p$ dan $K i$ sama sama dikalikan dengan nilai error sistem, sedangkan $K d$ dikalikan dengan delta error, sehingga karakter keluaran dari setiap konstanta berbeda. Nilai Ki sangat kecil (T) pada saat error besar (NB dan PB) agar sistem tidak mendapat nilai redaman sehingga respon yang dihasilkan semakin cepat. Sedangkan pada saat mendekati steady state, nilai $K d$ sangat besar $(\mathrm{H})$ sehingga redaman sistem akan mencegah terjadinya perubahan.

\section{HASIL DAN PEMBAHASAN}

Pada sistem kendali kestabilan ketinggian ini, dilakukan seperti halnya pengujian pada sudut pitch dan roll dimana dilakukan variasi terhadap rentang nilai konstanta PID yang akan ditala dengan metode fuzzy. Dari hasil variasi rentang didapatkan hasil terbaik yang ditunjukkan dengan respon sistem pada Gambar 4. Pengujian dilakukan dengan memberikan gangguan sebesar kurang lebih $43 \mathrm{~cm}$ dari setpoint ketinggian sebesar 70,00 $\mathrm{cm}$. Risetime yang didapat sebesar 0,6 detik, settling time sebesar 2,05 detik, dan dengan overshoot sebesar $6 \mathrm{~cm}$ atau sebesar $14 \%$ dari total gangguan. Sementara untuk pengujian tanpa gangguan didapatkan nilai pembacaan rata-rata nilai steady-state sebesar 69,02 $\mathrm{cm}$ dengan simpangan baku sebesar \pm $1,775 \mathrm{~cm}$. 


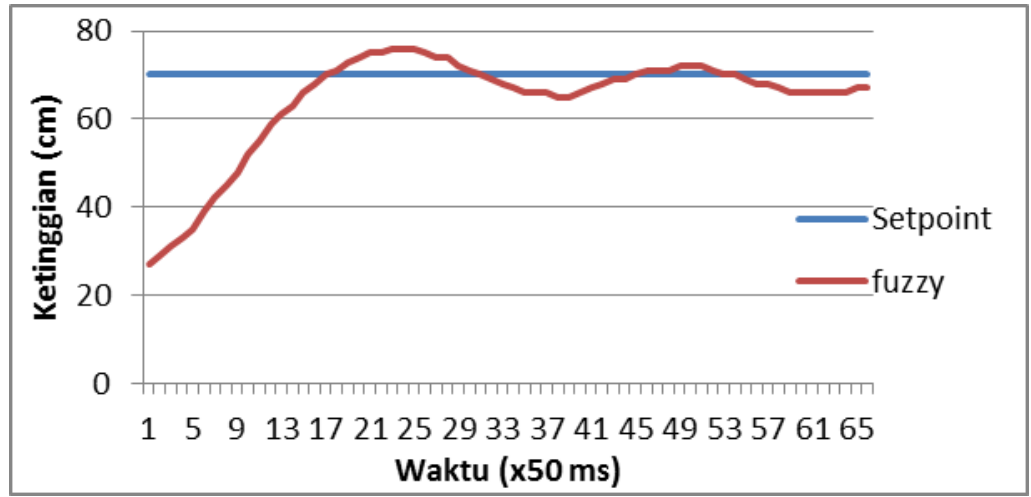

(a)

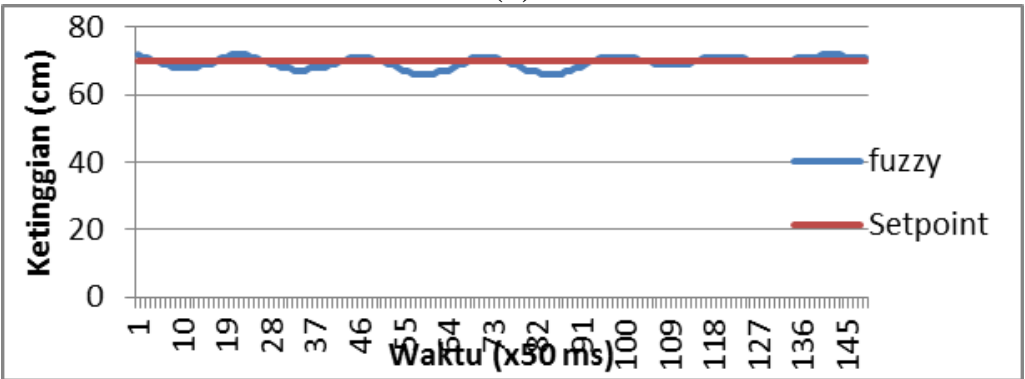

(b)

Gambar 4 Hasil pengujian PID Fuzzy kestabilan ketinggian dengan gangguan dan tanpa gangguan

Nilai rentang PID untuk kendali kestabilan ketinggian yang digunakan pada pengujian ini dapat dilihat pada Tabel 4.

Tabel 4 Rentang nilai konstanta PID ketinggian

\begin{tabular}{|l|l|l|l|}
\hline Konstanta & Nilai minimal & Nilai tengah & Nilai maksimal \\
\hline$K p$ & 0,110 & 0,112 & 0,114 \\
\hline$K i$ & 0,019 & 0,021 & 0,023 \\
\hline$K d$ & 0,029 & 0,030 & 0,031 \\
\hline
\end{tabular}

Penalaan konstanta PID oleh logika fuzzy terlihat pada Gambar 5.Pada gambar tersebut merupakan perubahan nilai konstanta yang awal respon terhadap gangguan sebesar $\pm 43 \mathrm{~cm}$ seperti pada Gambar 4 (a). Pada Gambar 5 (a) dan (b) merupakan nilai $K p$ dan $K d$ yang bernilai sama karena keduanya akan berubah berdasarkan nilai error yang terbaca. Terlihat pada hasil tersebut bahwa kedua konstanta bernilai besar saat mendapatkan gangguan yang besar. Nilai $K p$ dan $K i$ kemudian terlihat turun pada saat error mendekati $0 \mathrm{~cm}$ dan mencapai nilai terendah pada saat error bernilai 0. Sedangkan pada Gambar 5 (c) merupakan grafik perubahan nilai $K d$ pada gangguan yang sama.

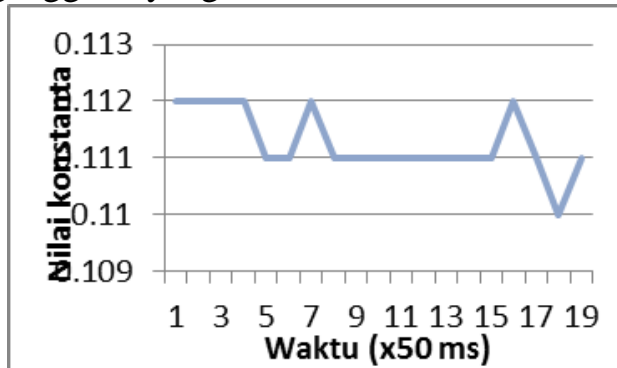

(a)

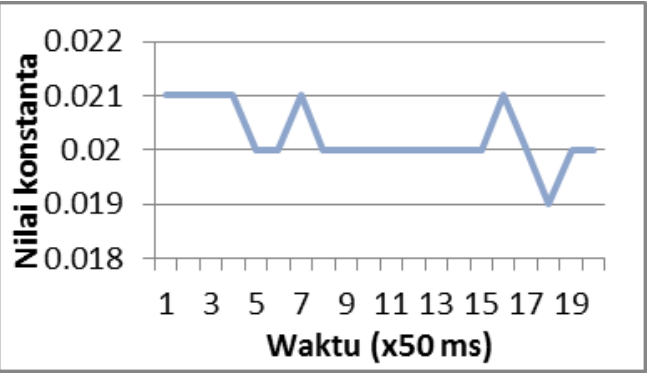

(b)

IJEIS Vol. 7, No. 1, April 2017: $61-70$ 


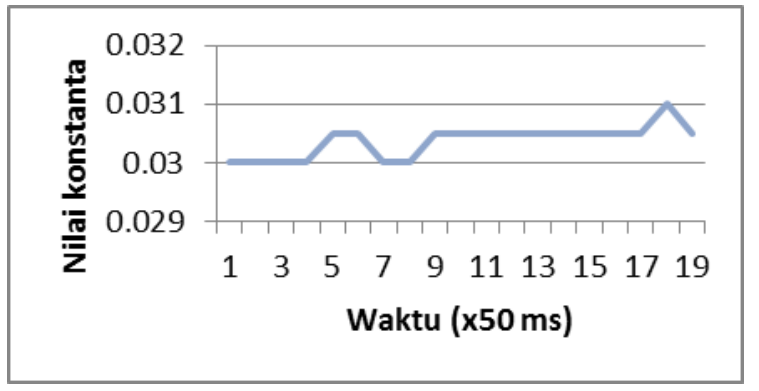

(c)

Gambar 5 Perubahan nilai terhadap error ketinggian pada (a) Kp (b) Ki (c) Kd

\section{KESIMPULAN}

Berdasarkan hasil pengamatan, pengujian dan analisis pada hasil yang diperoleh dari penelitian implementasi metode PID untuk menjaga kestabilan ketinggian terbang pada quadrotor dapat disimpulkan sebagai berikut:

1.Pengujian sistem kendali PID Fuzzy untuk menjaga kestabilan ketinggian dihasilkan tanggap sistem terbaik yang diperoleh yaitu rise time sebesar 0,6 detik, settling time sebesar 2,05 detik, dan percent overshoot sebesar $14 \%$ pada saat mendapatkan gangguan sebesar $43 \mathrm{~cm}$ dan nilai steady-state sebesar $(68,6 \pm 1,9) \mathrm{cm}$, menggunakan rentang input error sebesar $-50 \mathrm{~cm}$ hingga $50 \mathrm{~cm}$, dan input delta error dari $-10 \mathrm{~cm}$ hingga $10 \mathrm{~cm}$, serta dengan rentang output konstanta PID masing-masing $K p$ dari 0,110 hingga 0,114, Ki dari 0,019 hingga 0,023, dan $K d$ dari 0,029 hingga 0,031.

2.Pengujian sistem kendali PID Fuzzy untuk menjaga kestabilan sikap terbang quadrotor dengan menala mandiri dapat berjalan dengan rise time yang dihasilkan sebesar 0,2 detik dan settling time 0,75 detik pada saat mendapat gangguan pada sudut pitch sebesar $45,05^{\circ}$ dan sudut roll sebesar $31^{\circ}$ dengan overshoot sebesar $2,62^{\circ}$ dan rerata steady state error sebesar $1,31^{\circ}$, menggunakan rentang input error sebesar $-50^{\circ}$ hingga $50^{\circ}$ dan input deltaerror dari $-10^{\circ}$ hingga $10^{\circ}$, serta rentang output konstanta PID pada sudut pitch serta roll masing-masing $K p$ dari 0,119 hingga $0,121, K i$ dari 0,007 hingga 0,008, serta $K d$ dari 0,037 hingga 0,040.

Berdasarkan dari hasil penelitian yang disebutkan di atas, telah berhasil diimplementasikan metode penalaan konstanta PID secara mandiri berdasarkan logika Fuzzy pada quadrotor untuk menjaga kestabilan ketinggian terbang quadrotor.

\section{SARAN}

Ada beberapa hal yang perlu disempurnakan pada penelitian ini. Berikut saran yang dikemukakan untuk penelitian selanjutnya yang berhubungan dengan penelitian ini:

1. Penggunaan sistem kendali fuzzy dapat diuji pada quadrotor dengan gangguan dinamis di luar ruangan.

2. Penggunaan sistem kendali fuzzy dapat dikembangkan untuk menjalankan misi yang lebih rumit.

3. Penambahan kendali untuk menjaga sikap terbang quadrotor agar memudahkan misi kendali ketinggian yang lebih stabil.

\section{UCAPAN TERIMA KASIH}

Penulis mengucapkan terima kasih kepada seluruh pihak yang telah memberi dukungan moril maupun materil terhadap penelitian ini. 


\section{DAFTAR PUSTAKA}

[1] Bouabdallah, S., Noth, A. \& Siegwan, R., 2004. PID vs LQ Control Techniques Applied to an Indoor Micro Quadrotor.

[2]Fatan, M., Sefidgari, B. L., \& Barenji, A. V. (2013). An Adaptive Neuro PID for Controlling the Altitude of Quadcopter Robot Output of Plant, 662-665.

http://doi.org/10.13140/RG.2.1.2896.0804

[3]Mehranpour, M.R., 2013. A New Fuzzy Adaptive Control for a Quadrotor Flying Robot.

[4]Raza, S.A. \& Gueaieb, W., 2010. Intelligent Flight Control of an Autonomous Quadrotor.

[5]Ogata, K., 2010, Modern Control Engineering Fifth Edition, Fifth, Prentice Hall, New Jersey.

[6] Naba, A., 2009. Belajar Cepat Fuzzy Logic Menggunakan Matlab, ANDI OFFSET, Yogyakarta.

[7] Zadeh, L.A., 2004. Fuzzy Logic Systems: Origin, Concepts, and Trends.University of Carolina, Berkeley.

[8] Santos, M., Lopez, V., Morata, F., 2010, Intelegent Fuzzy Controller of Quadrotor, Universidad Complutense, Spain.

[9] Leong, B.T.M., Low, S.M. dan Ooi, M.P.-L., 2012, Low-Cost Microcontroller-based Hover Control Design of a Quadcopter, Procedia Engineering, [Online] 41 (Iris), 458-464, tersedia di DOI:10.1016/j.proeng.2012.07.198.

[10] Pogram, D.F., 2014, Implementasi Metode Penala Konstanta PID Berdasarkan Logika Fuzzy pada Quadrotor, Skripsi, FMIPA Universitas Gadjah Mada, Yogyakarta. 